\title{
The effect of large-area pulsed electron beam melting on the corrosion and microstructure of a Ti6Al4V alloy
}

\author{
*J.C.Walker ${ }^{1}$, J.W.Murray ${ }^{2}$, M.Nie ${ }^{1}$, R.B.Cook ${ }^{1}$, A.T.Clare ${ }^{2}$ \\ ${ }^{1}$ National Centre for Advanced Tribology at Southampton (nCATS), University of \\ Southampton, SO17 1BJ, UK \\ ${ }^{2}$ Institute for Advanced Manufacturing, University of Nottingham, NG7 2RD, UK \\ *Corresponding Author -j.walker@soton.ac.uk; jcw101@hotmail.com
}

Tel: +442380593761 Fax: +44 2380593016

\begin{abstract}
The use of titanium alloys in biomedical applications continues to increase due to the excellent stiffness to weight ratio and high corrosion resistance. In order to improve the surface wettability and corrosion properties of a Ti-6Al-4V alloy, the surface treatment method, large area electron beam melting technique was investigated. Polished samples were subject to pulsed treatments of 1, 15 and 25 at $1.38 \mathrm{~J} / \mathrm{cm}^{2}$ beam energy. Surface roughness and contact wetting angles were reduced as a result of the treatment. Microstructural analysis of the surface by XRD and FIB-TEM revealed a martensitic alpha prime phase formed as a result of the high cooling rates induced by the treatment. The presence of this homogenous martensite layer was shown to facilitate a compact passive oxide layer formation during corrosion, thus improving corrosion rates by several orders of magnitude compared to an untreated sample. Large area electron beam melting of Ti-6Al-4V induced a number of changes to the near surface microstructure of the samples, all of which could be used to tailor mechanical and corrosion properties to that of a desired application, without compromising the bulk material properties. These are explored in detail in this work.
\end{abstract}

Keywords: Large Area Electron Beam Melting; Pulsed electron beam irradiation; TEM; Corrosion; Martensite; Ti-6Al-4V; 


\section{Introduction}

Titanium alloys have seen extensive application in the biomedical sector, where their high stiffness to weight ratio, osseo-integration and relative resistance to corrosion in-vivo have meant widespread application in orthopaedic devices and dental implants [1-5]. The advantage of titanium over other metallic materials such as cobalt chromium or stainless steel resides in their lower elastic modulus which can reduce instances of stress shielding and encourage improved bone recovery and growth as a result. Despite the good corrosion resistance of titanium alloys, this can be compromised in-vivo by the removal of the nascent surface oxide layer by, for example, tribological asperity contact events [6]. In order to improve the manufacture and surface properties of titanium alloys, extensive research has been conducted into surface modification techniques such as laser or electron beam melting of titanium alloys to produce novel microstructures [1, 7-12]. More recently, the advent of Large Area Electron Beam Melting (LAEBM) has shown that a low energy defocused pulsed electron beam treatment can induce high cooling rates in the surface of electrically conducting metals, such that non-equilibrium phases are readily formed [13-16]. The technique offers the possibility of modifying the surface layer $(5-40 \mu \mathrm{m})$ only, such that the bulk mechanical properties of components are left un-affected by the treatment. Recent work using this technique on a number of pure and alloyed titanium compositions has shown that corrosion resistance appears to be improved [17-23]. The present research seeks to further the understanding of this effect by investigating the surface corrosion behaviour of a Ti-6Al-4V alloy subject to LAEBM treatment through a detailed understanding of microstructure evolution. Understanding the changes in surface microstructure using a focused ion beam (FIB) transmission electron microscopy (TEM) technique will enable surface and sub-surface contributions to be determined.

\section{Experimental Procedure}

\subsection{Material Preparation}

Samples of wrought Ti-6Al-4V were prepared as cylindrical samples of $9 \mathrm{~mm}$ diameter and $4 \mathrm{~mm}$ thickness using electro-discharge machining. The cylindrical surfaces of each sample were flat lapped using a Kemet 15 lapping machine and 
diamond abrasives down to $6 \mu \mathrm{m}$ and finished by hand using a $1 \mu \mathrm{m}$ diamond cloth wheel.

\subsection{Pulsed Electron Beam Treatment}

The polished Ti-6Al-4V surfaces were irradiated using a Sodick PF32A machine, a schematic of which is shown in Figure 1. The machine consists of a sample chamber, which was purged of air with nitrogen and pressurized to $0.05 \mathrm{~Pa}$ with argon gas which is the medium used for plasma build up. In this technique, a solenoid coil produces a magnetic field, at the maximum intensity of which a pulsed voltage of $5 \mathrm{kV}$ is applied to the anode and Penning discharge is initiated. After a duration of 50-100 $\mu \mathrm{s}$, the current of the Penning discharge reaches 150$170 \mathrm{~A}$, and a plasma column is formed near the anode. After a delay time of 10$30 \mu \mathrm{s}$, an accelerating voltage of $15 \mathrm{kV}$ used in this study, with a rise time of 20 $100 \mathrm{~ns}$ is applied to the cathode. The electric field is concentrated in a nearcathode ion layer and reaches values of up to $400 \mathrm{kV} / \mathrm{cm}$. Explosive emission takes place on the cathode causing a number of cathode spots (dense plasma clouds) to appear and emit electrons. The applied voltage is concentrated in a double-layer, between the cathode plasma and the anode plasma, in which electrons are accelerated and the beam is formed. The electron beam accelerated in the double layer is transported through the anode plasma to a collector cathode where the work piece is placed. Samples were treated at $15 \mathrm{kV}$ cathode voltage for 1, 15 or 25 pulses, translating to an energy input of $1.38 \mathrm{~J} / \mathrm{cm}^{2}$ [24], with constant time between pulses of 11 seconds. 


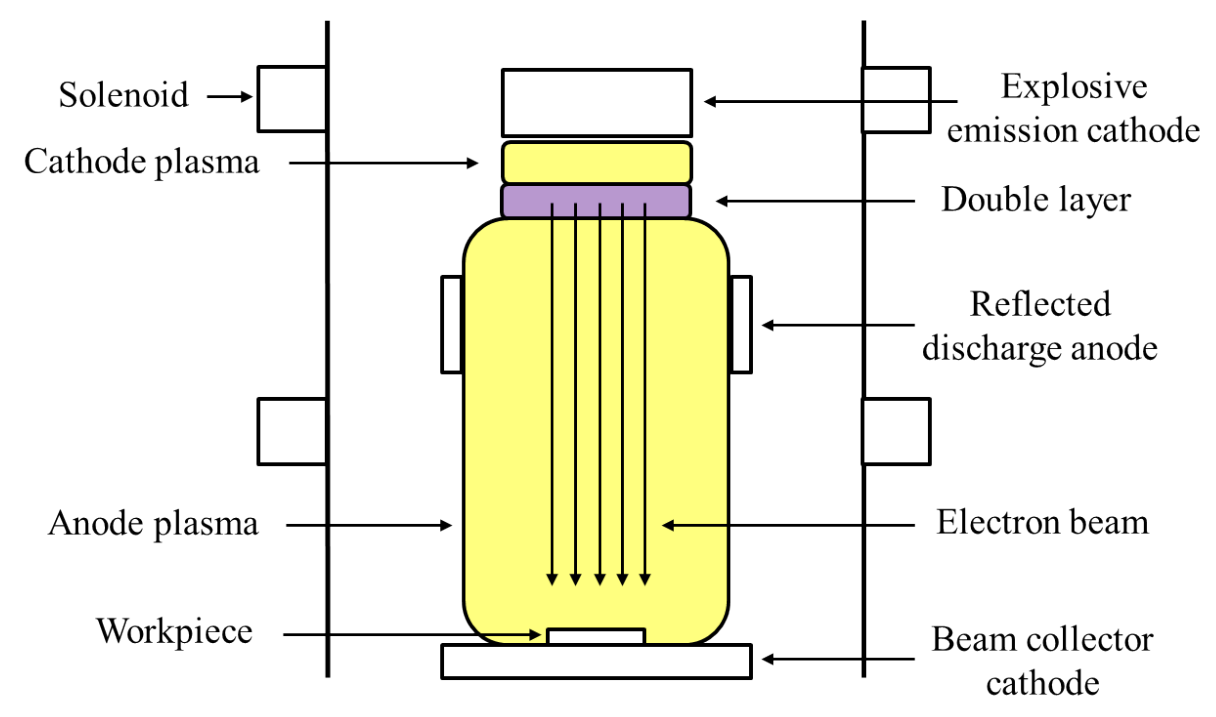

Figure 1. Schematic of the Sodick PF32A electron beam melting machine.

\subsection{Surface Roughness}

Surface roughness profiles were determined using an Alicona Infinite Focus noncontact profilometer. The technique utilises a focal plane variation approach to re-construct 3-dimensional topography of surfaces. Surfaces of both pre and post-EBM treated samples were reconstructed and average surface roughness $\left(\mathrm{R}_{\mathrm{a}}\right)$ values were determined from $1.25 \mathrm{~mm}$ trace lengths, filtered according to ISO 4287 using a $\mathrm{L}_{\mathrm{C}}$ cut-off wavelength filter of $0.25 \mathrm{~mm}$. A total of 8 measurements were made per sample, with the highest and lowest values being excluded from calculations of mean and standard deviation values.

\subsection{Surface Energy}

The surface wettability of the control and EBM treated surfaces was assessed using a Kruss DSA-100 drop shape analyser. $1 \mathrm{ml}$ sessile drops of distilled water were pipetted onto each surface and imaged with a digital camera. Circular fitting pattern software was used to determine the contact angle that the water made with the surface at each apex. A minimum of five drops per sample were used to measure an average and standard deviation error for each surface.

\subsection{Electrochemical behaviour}

The corrosion characteristics of various treated specimens were evaluated by measuring open circuit potentials (OCP) and cyclic polarization curves (CPC). All electrochemical measurements were performed in aerated solutions using a 
potentiostat (Gamry REF600, USA) and an electrochemical multiplexer (Gamry ECM8, USA) in a Faraday cage at room temperature. A graphite rod and a double-junction $\mathrm{Ag} / \mathrm{AgCl}$ in $3.5 \mathrm{M} \mathrm{KCl}$ electrode were used as counter and reference electrodes, respectively. The disc specimen as working electrode was embedded within a plastic sample holder with a geometrically exposed surface area of $0.283 \mathrm{~cm}^{2}$.

All electrochemical tests were conducted by monitoring OCPs for $1 \mathrm{~h}$ followed by cyclic polarization measurements. Cyclic polarization curves were carried out up to the applied potential of $+4.0 \mathrm{~V}$ against the measured OCP or the anodic current density of $0.050 \mathrm{~mA} / \mathrm{cm}^{2}$ at a scan rate of $0.5 \mathrm{mV} / \mathrm{s}$.

\subsection{Surface Microstructural Analysis}

Scanning electron microscopy of the EBM treated surfaces was carried out using a Zeiss NVision 40 dual beam FEG-SEM microscope operating at $5 \mathrm{kV}$ accelerating voltage and x5000 magnification. The machine is equipped with a $\mathrm{Ga}^{+}$liquid metal focused ion beam source, which was used to investigate the sub-surface micro-structural behaviour of the sample treated at $15 \mathrm{kV}$ and 25 pulses after electro-chemical corrosion. The surface of the sample was first protected from beam damage by deposition of a layer of carbon from a pre-cursor gas. During the initial stages of ion-assisted deposition, damage to the upper few nanometers can occur. As such, an electron-assisted deposition of carbon was utilised prior to accelerated ion-beam deposition, to build up a protective surface layer approximately $1 \mu \mathrm{m}$ thick. The focused ion beam was then used at an accelerating voltage of $30 \mathrm{kV}$ to sputter material from either side of the carbon deposition at beam currents between $150 \mathrm{pA}-3 \mathrm{nA}$. Once the sample was approximately $1 \mu \mathrm{m}$ in thickness it was cut from the sample surface and extracted using Kliendiek micro manipulators and fixed to a copper TEM grid, prior to thinning to electron transparency at a beam current of $80 \mathrm{pA}$.

\subsection{Transmission Electron Microscopy}

The thinned TEM lamella was investigated by the Zeiss NVision40, operating at $30 \mathrm{kV}$ in STEM mode. A mixture of bright and dark field modes were used to 
gather images from the four-quadrant electron detector. For higher magnification analysis a JEOL $2100 \mathrm{~F}$ TEM operating at $200 \mathrm{kV}$ was used to gather bright and dark field TEM and STEM images as well as electron energy loss spectroscopy profiles from the corroded surface.

\section{Results}

\subsection{Surface Roughness Values}

The measured average surface roughness of the three Ti-6Al-4V samples before and after the pulsed electron beam treatment is shown in Table 1, below. It can be seen that variations in the hand polishing process resulted in initial surface roughness differences of around $37 \mathrm{~nm}$. Whilst it appeared that a single pulse at $15 \mathrm{kV}$ appeared to increase the surface roughness, the $7 \mathrm{~nm}$ difference could be considered within the error bounds of one standard deviation. It was clear however that samples irradiated for a larger number of pulses of 15 and 25 experienced a drop in their surface roughness of 25 and $31 \mathrm{~nm}$ respectively, compared to the initial values.

\begin{tabular}{cccc}
\hline Sample & $\begin{array}{c}\text { Pre EBM } \\
\text { Roughness, } \mathrm{R}_{\mathrm{a}}(\mathrm{nm})\end{array}$ & $\begin{array}{c}\text { Post EBM } \\
\text { Roughness, } \mathrm{R}_{\mathrm{a}}(\mathrm{nm})\end{array}$ & Difference (nm) \\
\hline $15 \mathrm{kV}, 1$ Pulse & $100 \pm 5$ & $107 \pm 5$ & +7 \\
\hline $15 \mathrm{kV}, 15$ Pulses & $137 \pm 11$ & $112 \pm 4$ & -25 \\
\hline $15 \mathrm{kV}, 25$ Pulses & $125 \pm 8$ & $94 \pm 7$ & -31 \\
\hline Table 1. The influence of number of pulses on the average surface roughness, Ra, of the treated Ti-6Al-4V samples. Error
\end{tabular}
bounds are one standard deviation.

\subsection{Surface Morphology}

Figure $2 \mathrm{a}$ ) shows a secondary electron image of the untreated Ti-6Al-4V surface after mechanical polishing. Clearly visible were the mechanical polishing marks in the surface as a result of the diamond polishing stage. Figure 2 b) shows the sample treated at $15 \mathrm{kV}$ with a single pulse. It was noticeable that some of the polishing marks had been removed from the surface as a result of the EBM treatment, however, many of the deeper scratches still remained. This would result in a similar average surface roughness value, as discussed above, as the measure of $R_{a}$ is simply an arithmetic measure of the mean deviation of all points from an idealised surface. It can be seen in Figure 2 c) \& d) that the increased number of pulses had resulted in a complete removal of all polishing marks and the emergence of an equiaxed microstructure. It was interesting to note that 
there appeared to be an increase in the surface grain size between 15 and 25 pulses, from grains that appeared to be sub-micron in Figure 2 c) to greater than 2 microns in Figure 2 d).

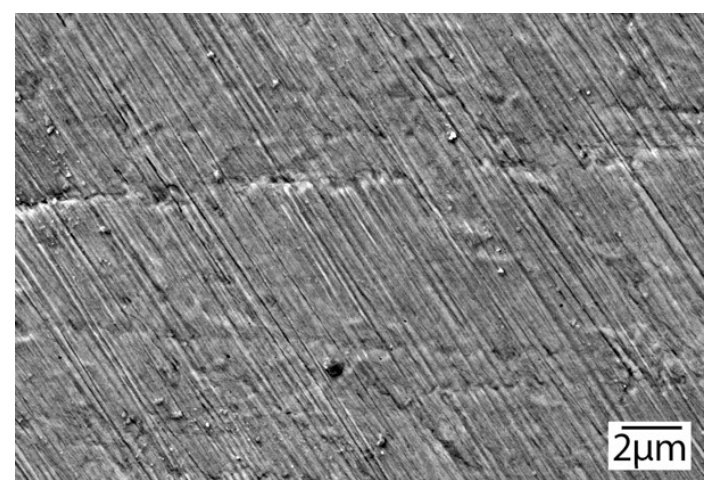

a) Polished Ti-6Al-4V alloy

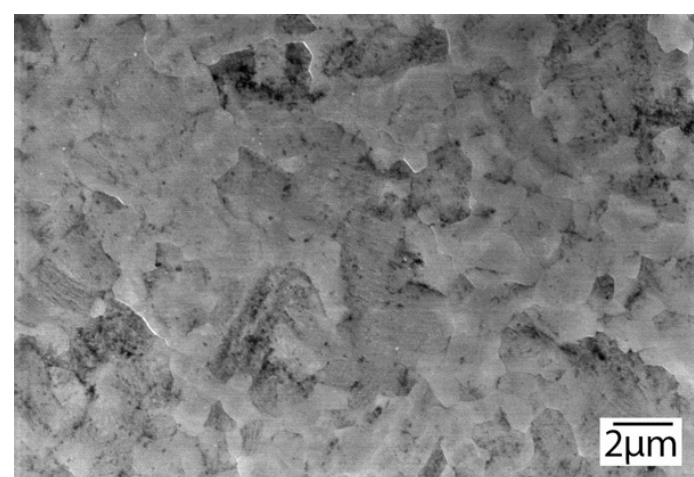

c) 15 Pulses, $15 \mathrm{kV}$

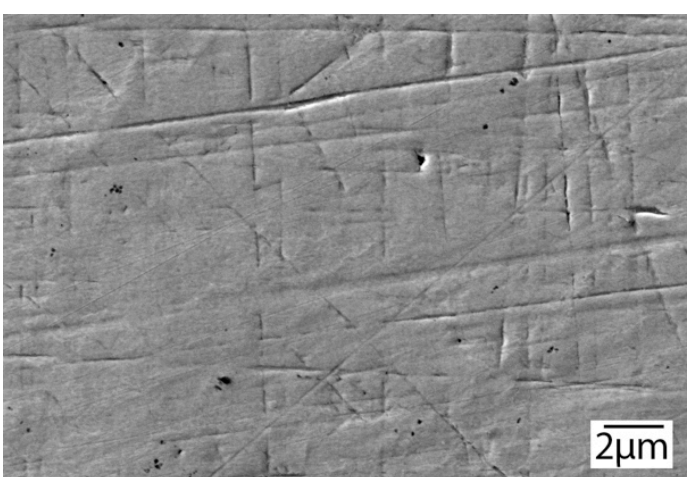

b) 1 Pulse, $15 \mathrm{kV}$

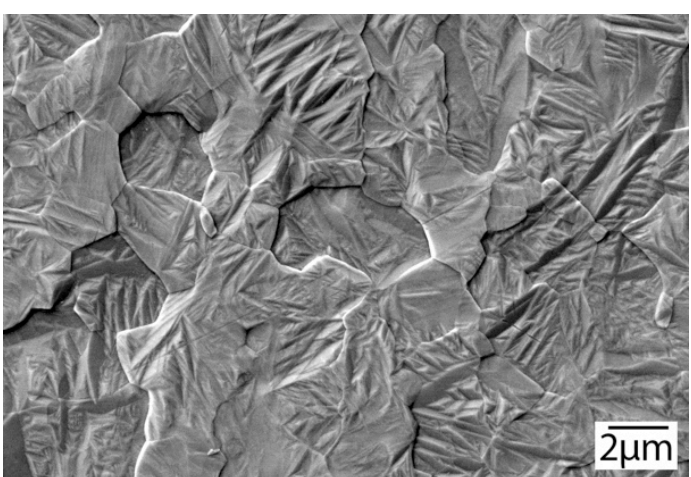

25 Pulses, $15 \mathrm{kV}$

Figure 2. Scanning electron microscopy images of the surface of Ti-6Al-4V EBM treated at different conditions.

\subsection{Surface Energy Wettability}

The LAEBM treatment process also caused a simultaneous drop in observed contact angles, Figure 3. The control specimen was the roughest of all surfaces and exhibited the most hydrophobic behaviour with a wetting angle of $79.4^{\circ}$. A reduction in the roughness as a result of the EBM process improved the hydrophilic nature of the surfaces, although a linear trend was not observed. Instead there appeared to be an optimal roughness for attaining the lowest surface energy, with contact angles of $53^{\circ}$ and $48^{\circ}$ for the single pulse and 15 pulse treated surfaces, respectively. Interestingly, whilst the 25 pulse treated surface exhibited the lowest surface roughness, the contact angle was between that of the other treated surfaces and the control. 


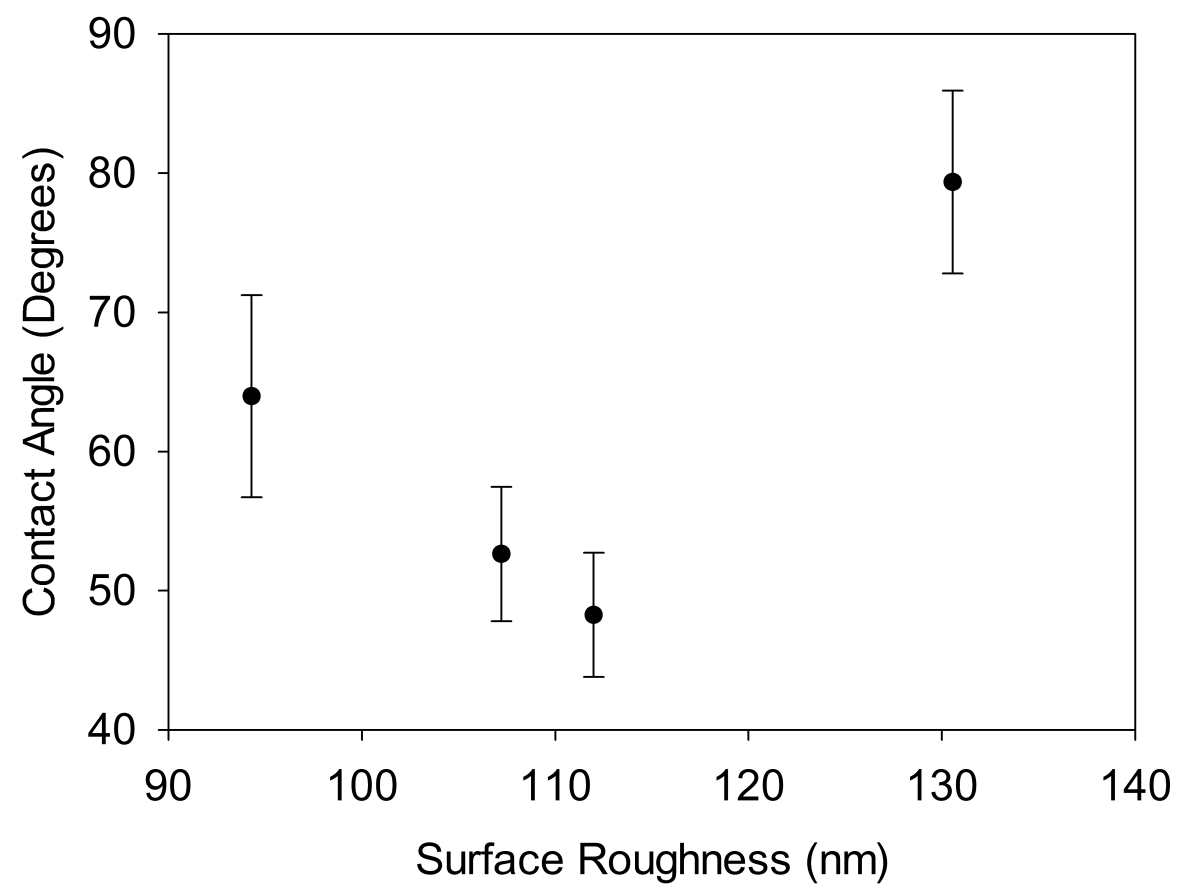

Figure 3. Plot of surface roughness vs contact angle for control and EBM treated Ti-6Al-4V surfaces.

\subsection{Corrosion behaviour}

The effect of LAEBM treatment on the corrosion behaviour of Ti-6Al-4V samples was investigated using different electrochemical techniques. OCP measurements and cyclic polarization curves were used to characterise corrosion properties in $3.5 \%$ (wt \%) solution and all the testing results obtained with different numbers of pulses were summarized in the Table 2. It can be seen that the OCP values all increased as a result of increasing number of pulses.

\begin{tabular}{ccccc}
\hline $\begin{array}{c}\text { Cathode } \\
\text { voltage }(\mathbf{k V})\end{array}$ & $\begin{array}{c}\text { Number } \\
\text { of Pulses }\end{array}$ & $\begin{array}{c}\mathbf{O C P} \\
\mathbf{( m V )}\end{array}$ & $\begin{array}{c}\mathbf{E}_{\mathbf{c o r r}} \\
\mathbf{( m V )}\end{array}$ & $\begin{array}{c}\text { Corrosion rate } \\
\left(\mathbf{1 0}^{-\mathbf{6}} \mathbf{m m p y}\right)\end{array}$ \\
\hline 0 & 0 & -313.8 & -307.0 & 923.2 \\
\hline 15 & 1 & -114.6 & -249.0 & 17.91 \\
\hline 15 & 15 & -66.10 & -166.0 & 5.478 \\
\hline 15 & 25 & -10.32 & -127.0 & 6.439 \\
\hline \multicolumn{5}{r}{ Table 2. Corrosion properties of e-beam treated samples in 3.5\% NaCl solutions. }
\end{tabular}

CPC results showed all the Ti-6Al-4V samples are resistant to pitting and crevice corrosion in $3.5 \% \mathrm{NaCl}$ solution at applied potentials up to $+4.0 \mathrm{~V}$. The corrosion potential $\left(\mathrm{E}_{\mathrm{corr}}\right)$ and corrosion rate were also estimated from the CPC measurements and summarized in Table 2. The results have been plotted in Figure 4 as a function of the number of pulses and again indicated that both OCP 
and Ecorr notably shifted in noble direction while corrosion rates decrease as the number of pulses in increased.

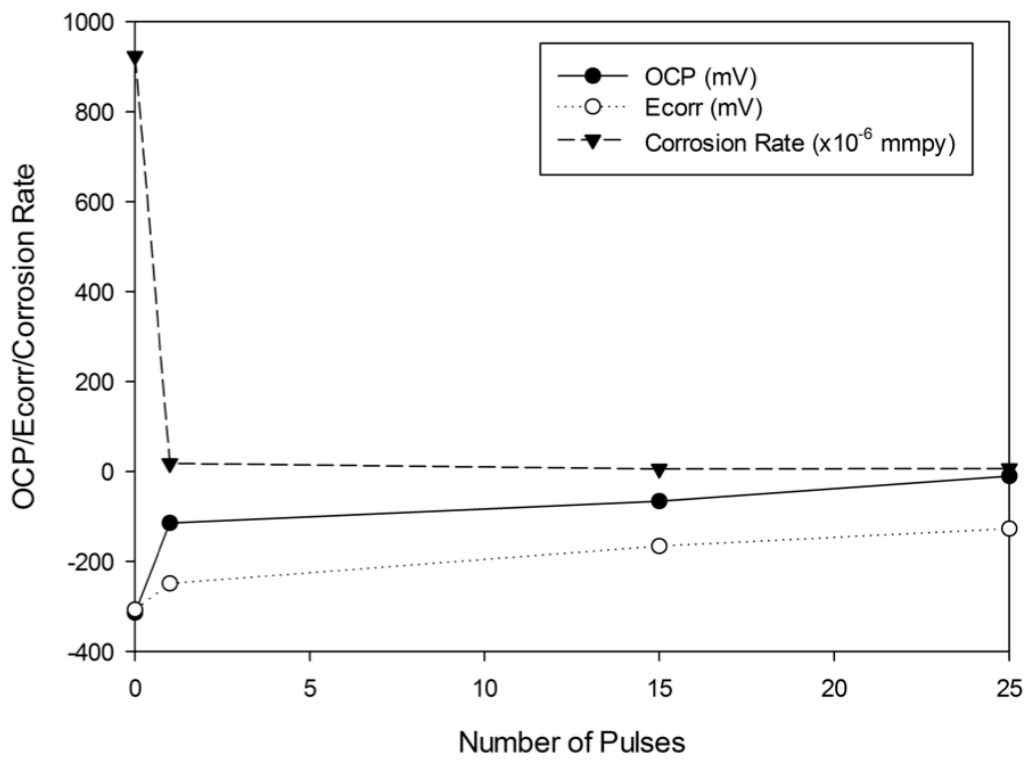

Figure 4. Effect of total surface energy input from pulsed EBM on the OCP, $\mathrm{E}_{\text {corr }}$ and estimated corrosion rate of Ti-6Al-4V surfaces.

\subsection{Sub-surface micro-structure}

In order to understand the improved surface corrosion behaviour, a FIB thinned lamella was produced from the surface of the $15 \mathrm{kV}, 25$ pulse treated sample, as shown in Figure 5. The dark area at the top was the electron and ion deposited carbon layer. Below this was noted a thin continuous layer that was bright in contrast. The near surface microstructure appeared consistent with a submicron microstructure. Approximately $2 \mu \mathrm{m}$ from the surface there appeared a transition to a more equiaxed micron sized grain structure, more consistent with the alpha-beta microstructure shown to be present in the XRD results of Figure 6 . The XRD results showed a general reduction in $\alpha$ peaks intensity as a result of the LAEBM process, coupled with a broadening of the peaks around $38-40^{\circ}$. 
Figure 5. Secondary electron image of the extracted FIB lamella sample prior to final thinning.

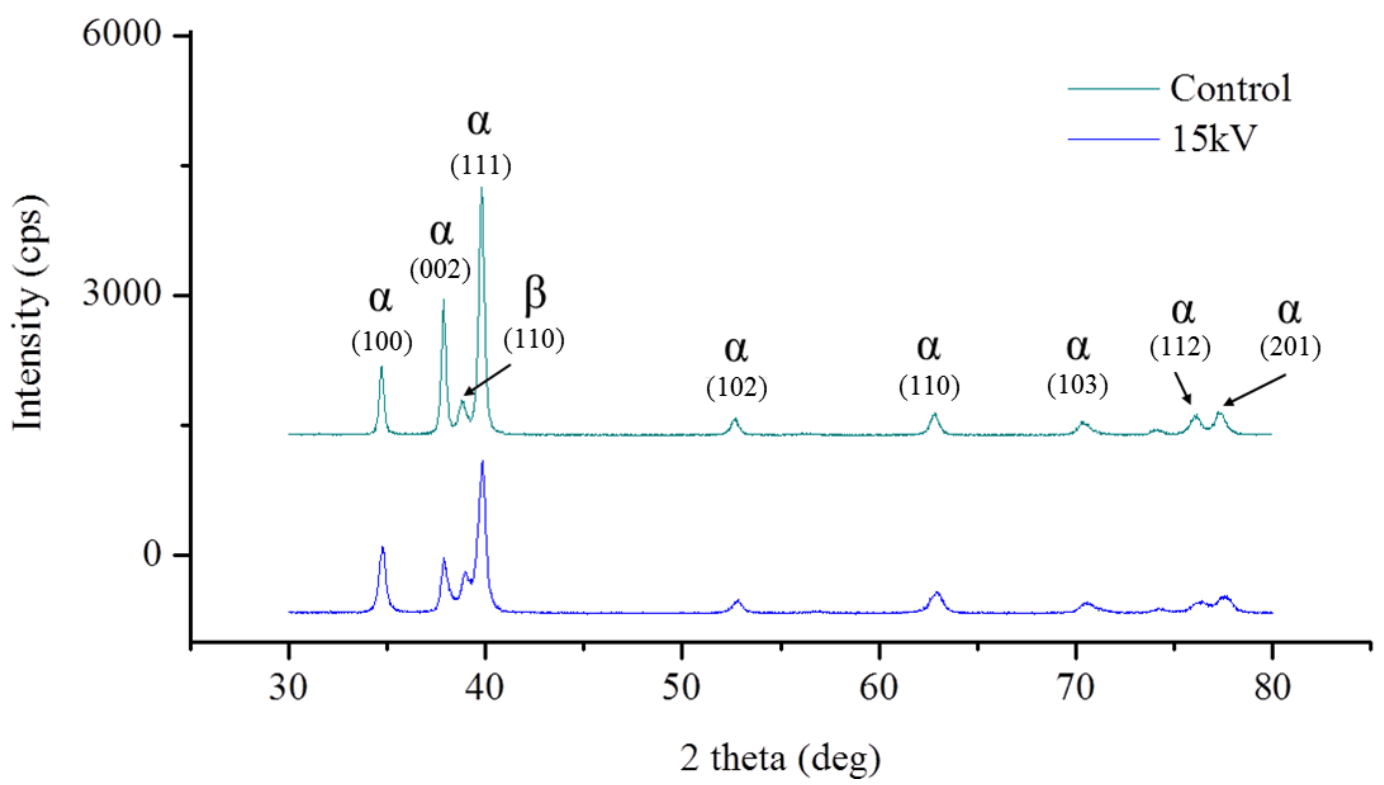

Figure 6. Bragg-Brentano $2 \theta$ XRD trace of polished and $15 \mathrm{kV} 25$ pulse EBM treated Ti-6Al-4V.

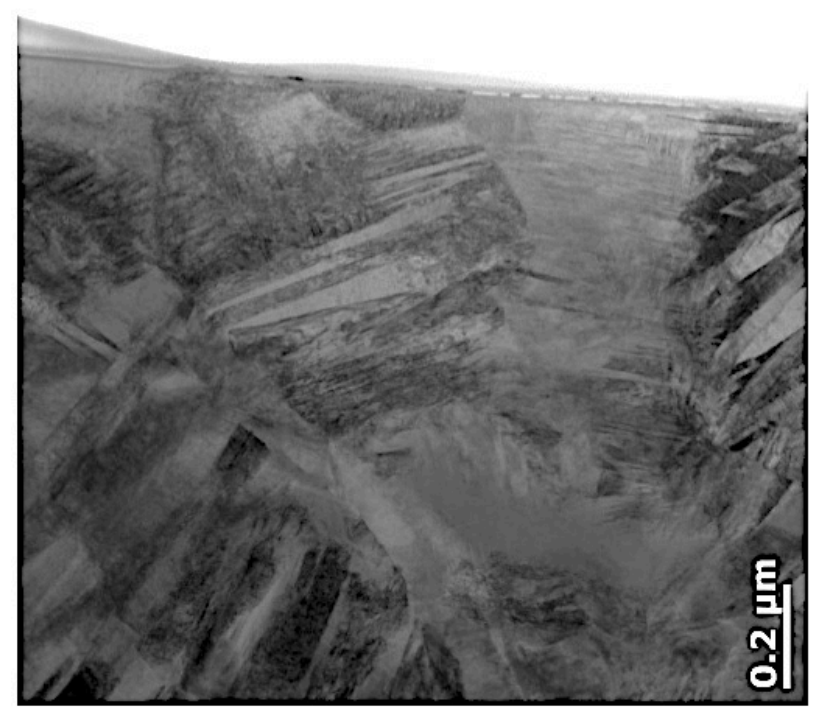

Figure 7. Bright field TEM image of the $15 \mathrm{kV}, 25$ pulse EBM treated Ti surface after corrosion. 

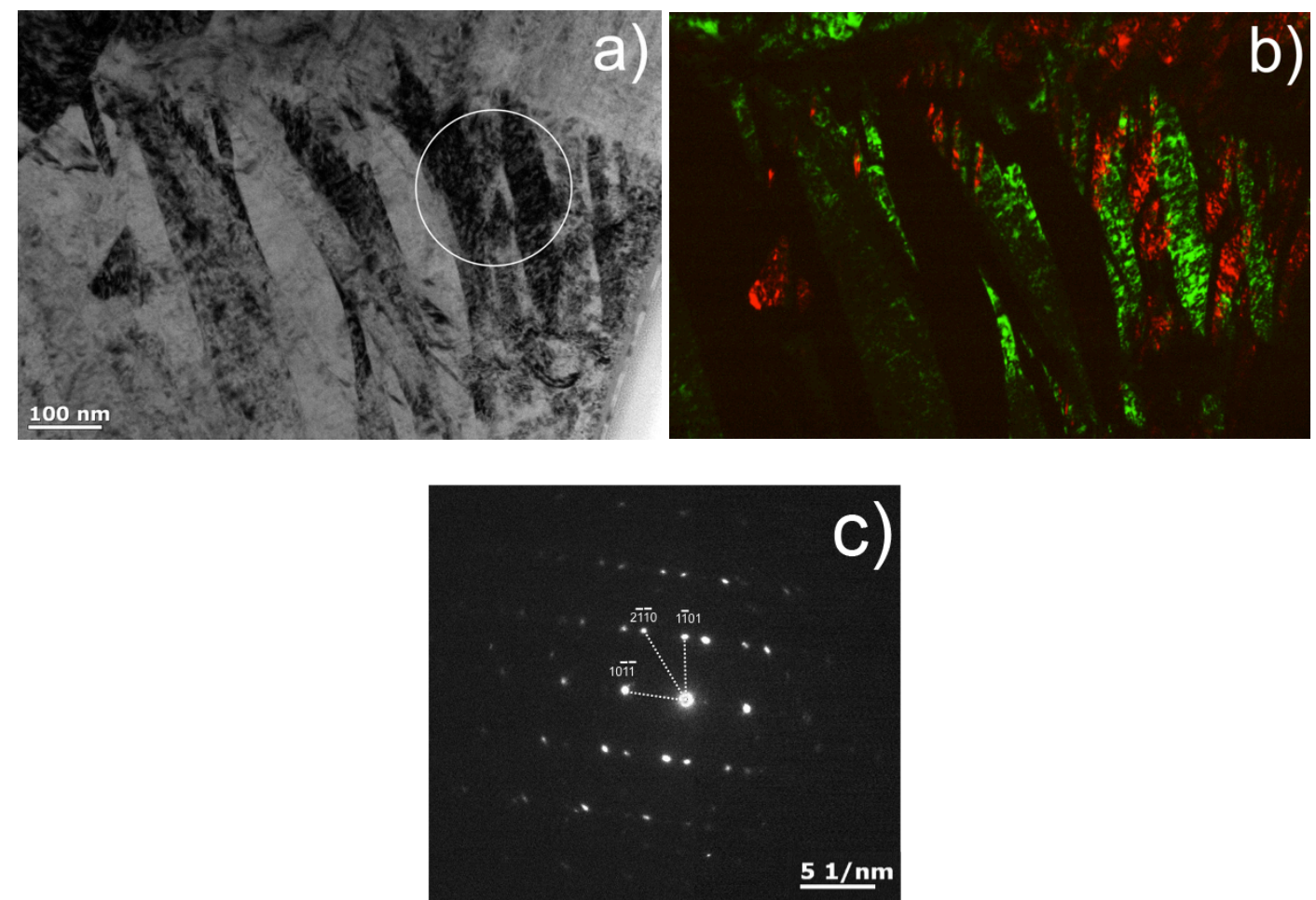

Figure 8. Bright (a) and pseudo-coloured dark field (b) images of $\alpha$-grain near the surface of the $15 \mathrm{kV}, 25$ pulse EBM treated Ti sample after corrosion. c) Selected area diffraction pattern from region indicated in a).

Figure 7 shows a bright field TEM image of the surface of the $15 \mathrm{kV}, 25$ pulse LAEBM treated Ti sample after corrosion. The near surface microstructure exhibited a fine acicular $\alpha^{\prime}$ martensite lathe structure within prior $\beta$ grain boundaries. Figure 8 shows bright and pseudo-coloured dark field images of the Ti grains near the surface of the sample. Dark field images were taken from the two spots about the $1 \overline{1} 01$ point and combined into a pseudo-coloured dark-field image, Figure $8 \mathrm{~b}$ ). It can be seen from both the SAED pattern and dark field image that $\alpha^{\prime}$ martensite twins were present within the elongated grains.

The thin surface layer noted in Figure 5 is shown in more detail in the HREM image in Figure 9. The general region marked 1 was a crystalline $\alpha^{\prime}$-Ti grain, whilst region 2 was a surface oxide layer approximately $18 \mathrm{~nm}$ in thickness. This was confirmed by an EELS line profile across this surface layer, shown in Figure 10. It can be seen that whilst the titanium content of the layer was constant compared to the bulk, there was a significant peak in the oxygen signal associated with this surface layer. Region 3 was a thin layer of electron beam 
assisted deposited carbon, approximately $7 \mathrm{~nm}$ thick, whilst region 4 was the amorphous ion beam deposited carbon used to protect the sample during the FIB preparation stage.

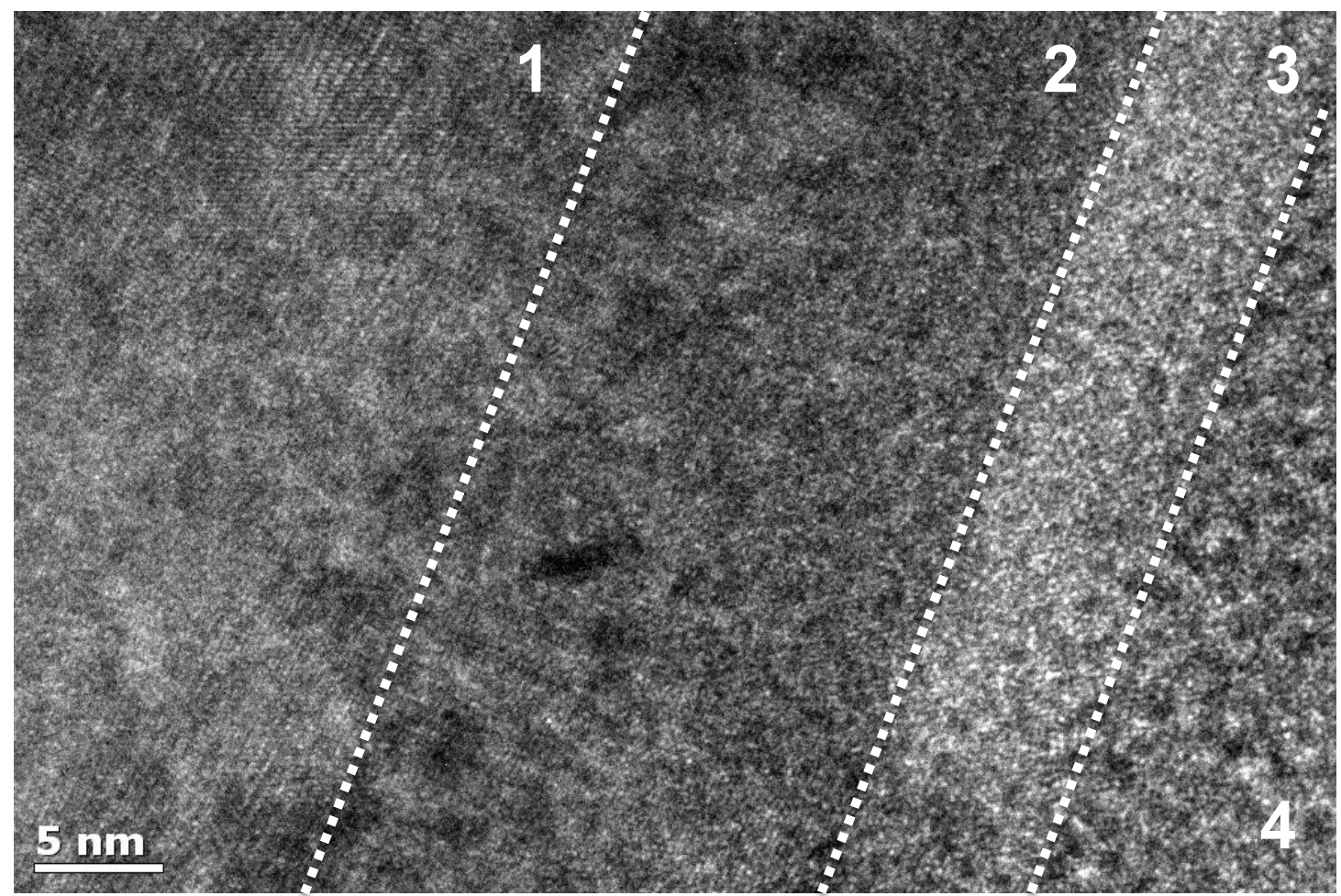

Figure 9. HREM image of the surface interface: 1- $\alpha$ '-Ti grain; 2- Oxide layer; 3 Electron deposited carbon; 4 - Ion deposited carbon.
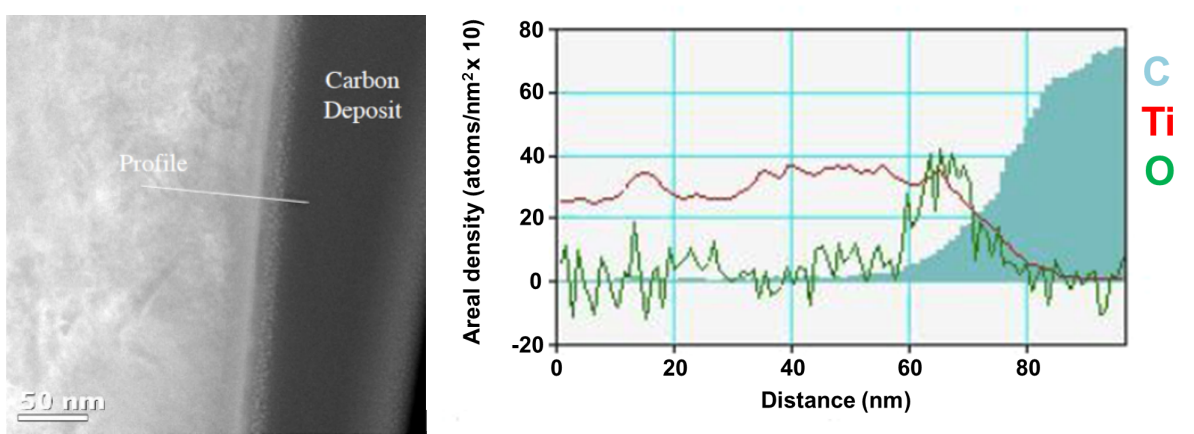

Figure 10. a) Dark field STEM image and b) EELS line profile across corroded surface layer.

\section{Discussion}

\subsection{Surface Properties}

Large area electron beam melting of Ti-6Al-4V induced a number of changes to the near surface microstructure of the samples, all of which could be used to tailor mechanical and corrosion properties to that of a desired application, without compromising the bulk material properties. 
It was clear from the surface electron images in Figure 2 and the non-contact surface profilometry results shown in Table 1 that the LAEBM process had resulted in a clear smoothing of the surface arising from the sample preparation process. This evolution is clearly shown in Figure 2. Figure 2 b) in particular showed the initial stages of electron beam induced surface polishing after only a single pulse treatment at $15 \mathrm{kV}$ cathode voltage, equivalent to a total surface energy input of $1.38 \mathrm{~J} / \mathrm{cm}^{2}$ [24]. Whilst the surface appeared smoother, deeper scratches still remained and resulted in no change in the measurable surface roughness. This was largely consistent with previous LAEBM on the same alloy by Gao [17] and Okada et al [20], the latter showing sharp edges resulting from a ball end mill were rounded at a beam energy of $1.2 \mathrm{~J} / \mathrm{cm}^{2}$, without a significant change in the overall $\mathrm{R}_{\mathrm{z}}$ value. Absolute values of surface roughness, $\mathrm{R}_{\mathrm{a}}$, in this study were lower than that observed by Guo et al [18], however it must be noted that their incident beam energies were notably higher $\left(9 \mathrm{~J} / \mathrm{cm}^{2}\right)$, resulting in large surface crater formation.

The surface free energy of the Ti-6Al-4V was lowered by the LAEBM treatment, as shown in Figure 3. Whilst this could be considered to be as the result of a reduction in the surface roughness, a linear trend was not observed, i.e. the lowest surface roughness did not produce the lowest wetting angle. Instead the optimal hydrophilic surface was obtained using a $15 \mathrm{kV}, 15$ pulse treatment suggesting that the surface wettability was largely controlled by the surface composition as well as the topography and similar to studies of laser treated steel and titanium surfaces [8,9]. The enhanced oxide film of titanium is well known to be more hydrophilic due to the $-\mathrm{OH}$ and $-\mathrm{O}^{2-}$ groups formed on the outermost layer [25].

However, the results were in contrast to LAEBM treatments on Ti-6Al-4V performed by Okada et al [19], where increasing energy input caused an increase in the surface hydrophobicity, up to a maximum of $95^{\circ}$ for an energy input of 6 $\mathrm{J} / \mathrm{cm}^{2}$. The precise reasons for this increase were not immediately clear, but it appeared that increasing input energy density per pulse did not have the same effect as increasing the number of pulses at the same energy. In terms of 
improving the surface wettability, particularly for applications in the biomedical sector where wettability and surface micro-architecture lead to greater osseointegration of cellular material with implant prostheses $[25,26]$, it seems that low energy dosing of the surface was preferential.

\subsection{Microstructural changes}

LAEBM of Ti-6Al-4V surfaces at a low energy density of $1.38 \mathrm{~J} / \mathrm{cm}^{2}$ resulted in no obvious microstructural change after a single pulse treatment at $15 \mathrm{kV}$, in contrast to samples treated with multiple pulses at $15 \mathrm{kV}$, as shown in Figures 2 c) and d), where the emergence of an equiaxed grain morphology occurred. Within these grains, the presence of needle like $\alpha^{\prime}$ hexagonal martensitic phases were observed contained within prior $\beta$ grain boundaries and were consistent to previous studies using this technique [17, 18, 22, 23]. The formation of this phase occurs due to the rapid quenching rate of the near surface, effecting a diffusionless $\beta$ to $\alpha^{\prime}$ phase transformation at a high enough cooling rate to preclude transformation by nucleation and growth. Cross sectional TEM analysis showed that the subsurface microstructure was consistent with the formation of martensitic laths within $2 \mu \mathrm{m}$ of the surface [27-29]. The $\alpha^{\prime}$ phase is similar in its hcp structure and lattice parameter to the original $\alpha$ phase, however, the reduction in intensity and broadening of the XRD peaks around $38-40^{\circ}$ in Figure 6 also point as evidence to the presence of the martensite phase and are consistent with results shown by Zhang et al [22, 23, 30].

The surface treated layer was of a similar thickness to other studies of Ti-6Al-4V processed by LAEBM, exhibiting a sharp interface with the underlying bulk material, approximately $2 \mu \mathrm{m}$, Figure 5 . The $\beta$ phase peak was thought to originate from further from the surface, towards the bulk of the sample, as Figure 8 has demonstrated the presence of a purely $\alpha^{\prime}$ phase near the surface [23]. The selected area diffraction pattern in Figure 8 which indicated the presence of $\alpha^{\prime}$ martensite twins was consistent with work by Manero et al [31] who observed the presence of misfit dislocations and large $\{1 \overline{1} 01\}$ twins within $\alpha^{\prime}$ martensite plates resulting from the accommodation of the $\beta \rightarrow \alpha^{\prime}$ transformation. 


\subsection{Corrosion Resistance}

The corrosion resistance of the LAEBM treated surfaces was significantly enhanced in $3.5 \% \mathrm{NaCl}$ solution compared to the untreated surface. It was shown in Table 2 that OCP values exhibited an increase with an increasing number of pulse treatments at $15 \mathrm{kV}$. It is well known that OCP changes with immersion time and can be used for monitoring corrosion behaviour of metallic alloys. A rise of potential in the positive direction indicates the formation of a passivating film and a subsequent steady potential indicates that the film remains intact and protective. A drop of potential in the negative direction indicates breaks in the film, dissolution of the film, or no film formation. It was clear from the high resolution TEM image in Figure 9 that a protective oxygen rich film had formed on the surface of the sample. The region indicated 1 in the image exhibited crystalline lattice planes and was associated with the $\alpha^{\prime}$ martensite phase. Region 2 was an approximately 18nm thick oxide layer, as indicated by the EELS spectra in Figure $10 \mathrm{~b}$ ) and was responsible for the enhanced corrosion protection observed for the LAEBM treated surfaces. The thickness of the protective oxide film formed on titanium alloys at open circuit conditions is typically $1-4 \mathrm{~nm}[29,32]$, therefore the extent of the continuous protective passive layer film formed during the open circuit and cyclic polarisation tests was significant. The homogenisation of the near surface layer to a single phase $\alpha^{\prime}$ structure, rather than a dual phase $\alpha+\beta$ was believed to be a direct contributor to the lower corrosion rates [18]. Studies into the rapid quenching of Ti-6Al-4V alloys have shown evidence that such martensitic structures do indeed exhibit lower corrosion rates [12, 29]. It has been shown that the enrichment of alloying elements vanadium in the $\beta$ phase and aluminium in the $\alpha$ phase leads to preferential dissolution of the $\beta$ phase by chlorine ions attacking vanadium oxides $[29,33,34]$. As solute partitioning does not occur during a diffusionless martensitic formation, the benefit of a stable $\alpha^{\prime}$ passive layer will remain. Observed corrosion rates of the untreated surface

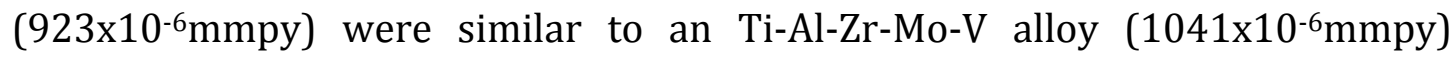
investigated by Zhang et al [23]. In contrast, corrosion rates of LAEBM treated surface in this study were as much as two orders of magnitude lower, 
highlighting the influence of differences in alloy chemistry on corrosion processes. There is also evidence $[18,23]$ that extending the number of pulse treatments beyond a certain threshold results in a reduction in the observed corrosion resistance, highlighted in the present study by a reduction in the corrosion rate, Table 2 , for the 25 pulse treatment. This may be due to changes in cooling rate associated with samples treated with a large number of pulses affecting the resulting surface microstructure development, however, clearly more work is required to verify this.

\section{Conclusions}

- LAEBM treatment of a polished Ti-6Al-4V alloy surfaces resulted in a reduction in surface roughness and an improvement in surface hydrophilic behaviour, although there was not a direct linear relationship between the two. This was believed to be the result of surface chemistry effects as well as topography.

- For treatments performed at 15 and 25 pulses, a homogenous $\alpha^{\prime}$ martensitic surface layer was generated, characterised by needle like features within prior $\beta$ grain boundaries.

- The surface layer appeared to significantly improve the corrosion behaviour of the treated components, in some cases lowering the corrosion rates by two orders of magnitude. This was shown to be the result of a uniform and continuous passive surface film which formed on the surface of the martensitic surface layer.

\section{Acknowledgements}

The authors would like to thank both the Southampton Nano-fabrication Centre for access to the dual-beam Zeiss NVision40 microscope and Dr Mike Fay for operation of the TEM at the Nottingham University Nanotechnology and Nanoscience Centre.

\section{References}

[1] L. Murr, S. Quinones, S. Gaytan, M. Lopez, A. Rodela, E. Martinez, D.

Hernandez, E. Martinez, F. Medina, R. Wicker, Microstructure and mechanical 
behavior of Ti-6Al-4V produced by rapid-layer manufacturing, for biomedical applications, J. Mech. Behav. Biomed. Mater., 2 (2009) 20-32.

[2] L. Le Guéhennec, A. Soueidan, P. Layrolle, Y. Amouriq, Surface treatments of titanium dental implants for rapid osseointegration, Dent. Mater., 23 (2007) 844854.

[3] M. Semlitsch, Titanium alloys for hip joint replacements, Clin. Mater., 2 (1987) 1-13.

[4] M.B. Nasab, M.R. Hassan, Metallic biomaterials of knee and hip-a review, Trends Biomater. Artif. Organs., 24 (2010) 69-82.

[5] M. Long, H. Rack, Titanium alloys in total joint replacement-a materials science perspective, Biomaterials, 19 (1998) 1621-1639.

[6] W. Rostoker, J. Galante, The influence of titanium surface treatments on the wear of medical grade polyethylene, Biomaterials, 2 (1981) 221-224.

[7] Z. Han, H. Zhao, X. Chen, H. Lin, Corrosion behavior of Ti-6Al-4V alloy welded by scanning electron beam, Mat. Sci. Eng. A-Struct, 277 (2000) 38-45.

[8] L. Hao, J. Lawrence, The Effects of CO2 Laser Radiation on the Wettability Characteristics of a Titanium Alloy, John Wiley \& Sons Ltd, Chichester, UK, 2006. [9] J. Lawrence, L. Li, Wettability characteristics of carbon steel modified with C02 Nd: YAG excimer and high power diode lasers, Appl. Surf. Sci., 154 (2000) 664-669.

[10] A. Safdar, L.-Y. Wei, A. Snis, Z. Lai, Evaluation of microstructural development in electron beam melted Ti-6Al-4V, Mater. Charact., 65 (2012) 8-15. [11] X. Wu, J. Liang, J. Mei, C. Mitchell, P. Goodwin, W. Voice, Microstructures of laser-deposited Ti-6Al-4V, Mater. Des., 25 (2004) 137-144.

[12] T. Yue, T. Cheung, H. Man, The effects of laser surface treatment on the corrosion properties of Ti-6Al-4V alloy in Hank's solution, J. Mater. Sci. Lett., 19 (2000) 205-208.

[13] D.I. Proskurovsky, V.P. Rotshtein, G.E. Ozur, A.B. Markov, D.S. Nazarov, V.A. Shulov, Y.F. Ivanov, R.G. Buchheit, Pulsed electron-beam technology for surface modification of metallic materials, J Vac. Sci. Technol. A, 16 (1998) 2480-2488. [14] J. Walker, R. Cook, J. Murray, A. Clare, Pulsed electron beam surface melting of CoCrMo alloy for biomedical applications, Wear, 301 (2013) 250-256. 
[15] V. Rotshtein, A. Markov, Y. Ivanov, Surface treatment of materials with lowenergy, high-current electron beam, in: Y. Pauleau (Ed.) Materials surface processing by directed energy techniques, Elsevier, Oxford, 2006, pp. 205-240. [16] V.P. Rotshtein, D.I. Proskurovsky, G.E. Ozur, Y.F. Ivanov, A.B. Markov, Surface modification and alloying of metallic materials with low-energy high-current electron beams, Surf. Coat. Tech., 180-181 (2004) 377-381.

[17] Y. Gao, Surface Modification of TC4 Titanium Alloy by High Current Pulsed Electron Beam (HCPEB) with Different Pulsed Energy Densities, J. Alloy. Compd., (2013).

[18] G. Guo, G. Tang, X. Ma, M. Sun, G. Ozur, Effect of high current pulsed electron beam irradiation on wear and corrosion resistance of Ti6Al4V, Surf. Coat. Tech., (2012).

[19] A. Okada, Y. Uno, K. Uemura, P. Raharjo, J. McGeough, Surface modification for orthopaedic titanium alloy by wide-area electron beam, P. I. Mech. Eng. B - J. Eng., 221 (2007) 173-178.

[20] A. Okada, Y. Uno, N. Yabushita, K. Uemura, P. Raharjo, High efficient surface finishing of bio-titanium alloy by large-area electron beam irradiation, J. Mater. Process. Tech., 149 (2004) 506-511.

[21] J. Tokunaga, T. Kojima, S. Kinuta, K. Wakabayashi, T. Nakamura, H. Yatani, T. Sohmura, Large-area electron beam irradiation for surface polishing of cast titanium, Dent. Mater. J., 28 (2009) 571-577.

[22] X. Zhang, S. Hao, X. Li, C. Dong, T. Grosdidier, Surface modification of pure titanium by pulsed electron beam, Appl. Surf. Sci., 257 (2011) 5899-5902.

[23] X. Zhang, J. Zou, S. Weber, S. Hao, C. Dong, T. Grosdidier, Microstructure and property modifications in a near $\alpha$ Ti alloy induced by pulsed electron beam surface treatment, Surf. Coat. Tech., 206 (2011) 295-304.

[24] Y. Daichi, Z. Wang, K. Yamazaki, S. Sano, Investigation of the formation and energy density of high-current pulsed electron beams, Plasma Chem. Plasma P., 27 (2007) 458-472.

[25] G. Zhao, A. Raines, M. Wieland, Z. Schwartz, B. Boyan, Requirement for both micron-and submicron scale structure for synergistic responses of osteoblasts to substrate surface energy and topography, Biomaterials, 28 (2007) 2821-2829. 
[26] F. Rupp, L. Scheideler, N. Olshanska, M. De Wild, M. Wieland, J. Geis -

Gerstorfer, Enhancing surface free energy and hydrophilicity through chemical modification of microstructured titanium implant surfaces, J. Biomed. Mater Res. A, 76 (2006) 323-334.

[27] T.F. Broderick, A.G. Jackson, H. Jones, F.H. Froes, The effect of cooling conditions on the microstructure of rapidly solidified Ti-6Al-4V, Metall Trans A, 16 (1985) 1951-1959.

[28] T. Ahmed, H. Rack, Phase transformations during cooling in $\alpha+\beta$ titanium alloys, Mat. Sci. Eng. A-Struct, 243 (1998) 206-211.

[29] I. Cvijović-Alagić, Z. Cvijović, S. Mitrović, V. Panić, M. Rakin, Wear and corrosion behaviour of $\mathrm{Ti}-13 \mathrm{Nb}-13 \mathrm{Zr}$ and $\mathrm{Ti}-6 \mathrm{Al}-4 \mathrm{~V}$ alloys in simulated physiological solution, Corros. Sci., 53 (2011) 796-808.

[30] L. Zeng, T.R. Bieler, Effects of working, heat treatment, and aging on microstructural evolution and crystallographic texture of $\alpha, \alpha^{\prime}, \alpha^{\prime \prime}$ and $\beta$ phases in Ti-6Al-4V wire, Mat. Sci. Eng. A-Struct, 392 (2005) 403-414.

[31] J. Manero, F. Gil, J. Planell, Deformation mechanisms of Ti-6Al-4V alloy with a martensitic microstructure subjected to oligocyclic fatigue, Acta Mater., 48 (2000) 3353-3359.

[32] C.E. Marino, E.M.d. Oliveira, R.C. Rocha-Filho, S.R. Biaggio, On the stability of thin-anodic-oxide films of titanium in acid phosphoric media, Corros. Sci., 43 (2001) 1465-1476.

[33] M. Metikos-Huković, A. Kwokal, J. Piljac, The influence of niobium and vanadium on passivity of titanium-based implants in physiological solution, Biomaterials, 24 (2003) 3765-3775.

[34] M. Atapour, A. Pilchak, G. Frankel, J. Williams, M. Fathi, M. Shamanian, Corrosion Behavior of Ti-6Al-4V with Different Thermomechanical Treatments and Microstructures, Corrosion, 66 (2010) 065004-065004-065009. 